\title{
La CONSTRUCCIÓN HISTÓRICA DEL SUJETO JOVEN EN MÉXICO
}

\author{
Historical Construction of the Young Subject in Mexico \\ Yannet Paz-Calderón \\ María Herlinda Suárez-Zozaya \\ Mónica Teresa Espinosa-Espíndola
}

Resumen: A través de una revisión histórica, en este texto se ofrece evidencia de que el establecimiento del capitalismo en México obligó a la identificación de un sector de población específico, el "sujeto joven", que fue esencial para la preparación y el aprendizaje de las virtudes laborales exigidas en el proceso de modernización productiva del país. Se demuestra que la construcción del "sujeto joven" estuvo ligada a un conjunto de leyes y normas, en términos jurídicos y educativos, encaminadas a que los niños tuvieran un tiempo de preparación para posteriormente incorporarse al mundo adulto. La principal conclusión es que el surgimiento del "sujeto joven" en México fue una exigencia del proceso de génesis y evolución del sistema capitalista nacional.

Palabras clave: jóvenes, mercado, trabajo, capitalismo.

Abstract: The main objective of this article is to provide evidence, based on a historical review, that the establishment of capitalism in Mexico forced acknowledgment of a specific sector of the population, i.e., youth, who were required to prepare and learn labor practices appropriate for the country as it developed and modernized. We show that this construction of the youthful subject was linked to a set of laws and rules that were established in legal and educational terms, thus giving children time to prepare to join the adult world. Our main conclusion is that the emergence of youth as a subject in Mexico was a requisite for the emergence and development of the country's current capitalist system.

Keywords: young, labor, market, capitalism.

\footnotetext{
Yannet Paz Calderón. Doctora en Economía Política del Desarrollo por la Benemérita Universidad Autónoma de Puebla, México. Profesorainvestigadora de la Universidad Tecnológica de la Mixteca, México. Temas de especialización: jóvenes y mercado de trabajo. Correo electrónico:ypaz@mixteco.utm.mx.

María Herlinda Suárez Zozaya. Doctora en Sociología por la Universidad Nacional Autónoma de México. Investigadora del Centro Regional de Investigaciones Multidisciplinarias (CRIM), de la Universidad Nacional Autónoma de México. Temas de especialización: jóvenes, mercado de trabajo y educación. Correo electrónico: ma_herlinda@yahoo.com.mx.
}

Mónica Teresa Espinosa Espíndola. Doctora en Administración por la Universidad Autónoma de Querétaro, México. Profesora-investigadora en la Universidad Tecnológica de la Mixteca, México. Temas de especialización: trabajo, cultura y empresa. Correo electrónico: monitte2005@hotmail.com.

Enviado a dictamen: 14 de junio de 2017

Aprobación: 25 de septiembre de 2017.

Revisiones: 2. 
L a juventud se ha concebido como una etapa de transición de la niñez a la vida adulta; es decir, se entiende como un tiempo de formación y preparación en el que se espera que de la escuela se pase al mundo del trabajo, de vivir con la familia original a establecer una propia, y de la dependencia económica a la independencia. Si bien estos procesos transitorios nunca han sido completamente lineales ni han carecido de obstáculos, actualmente se han tornado muy inquietantes (Balardini, 2000; Dávila, 2004). La importancia que hoy en día está tomando la población joven a nivel nacional e internacional es relevante no sólo por su cantidad, sino por los diversos retos que representa atender las necesidades de este sector, que van desde lo educativo hasta lo laboral, desde lo cultural a lo político, y un largo etcétera. En el caso particular de México, el desempleo juvenil es un problema al cual debe prestarse especial atención no sólo porque la fuerza de trabajo de este sector de la población no se esté utilizando para impulsar el crecimiento del país, sino por el crisol de situaciones que se derivan de las altas tasas de desocupación juvenil.

Por lo anterior, preguntarse qué significa ser joven hoy en día implica tomar en cuenta el conjunto de circunstancias y contextos que influyen en la construcción de las prácticas sociales, económicas, políticas y culturales de este sector de la población. Dar respuesta a esta interrogante no es fácil, sobre todo porque requiere de un ejercicio de pensamiento que permita evadir la homogeneización a la que conduce la manera común de definir a la juventud: a través de la edad. De esta manera, se ubica a estas personas, mecánicamente, en un supuesto "período de transición natural y lineal", en el paso de una condición de niños a adultos. La juventud es reducida idealmente a un período frágil y temporal de la vida (Paz y Campos, 2012).

Sin embargo, es necesario asumir una visión integral del fenómeno social a estudiar, por lo que, en este caso, se comenzará por problematizar la noción de juventud, para a partir de este punto analizar cómo se crean las condiciones para el surgimiento de: "un joven que vive en un tiempo y en un espacio específico".
Para ello habría que preguntarse: "[...] qué diferencia dicho tiempo joven y cuáles son las exigencias que se imponen al sujeto en este período vital, desde el discurso dominante del desarrollo" (Erazo, 2009: 1310). De esta manera, se puede afirmar que ser joven hoy en día tiene que ver con una forma de comportamiento social, económicamente creada, asignada e impuesta, y que está ligada a la historia del desarrollo del modo de producción imperante en México. En este sentido, la forma en que la sociedad moderna concibe a los jóvenes, y la manera en que éstos actúan y se desenvuelven en la sociedad, es resultado de la implantación y desarrollo del capitalismo en el país, idea principal que se desarrollará a lo largo de este trabajo.

La propuesta metodológica que se plantea en este documento parte de la indagación sobre las condiciones históricas y los cambios en la dinámica socioeconómica, en los que el sujeto joven emergió como respuesta a la generación de nuevas demandas y nuevos problemas productivos. Por ejemplo, Criado señala que: "Cuando cambias las condiciones de reproducción de los grupos sociales, y por tanto las condiciones sociales y materiales de producción de nuevos miembros, es cuando se producen diferencias de generación: los nuevos miembros son generados de manera distinta" (Criado, 1998: 83).

En este documento se sostiene la premisa de que existe un sujeto social específico destinado a cada mercado de trabajo, que es resultado de un momento histórico en particular. El objetivo de esta investigación es averiguar cómo se comenzó a moldear el sujeto joven a través del surgimiento de un mercado de trabajo específico, que constituye el medio por el cual el capitalismo transmite las exigencias que en términos laborales necesita para su funcionamiento. De inicio, se exponen los antecedentes históricos de la construcción del sujeto joven en México, en particular en el contexto urbano; posteriormente se hace una reflexión desde un enfoque lógico-histórico que permita abordar la construcción del sujeto joven desde su invención como un sujeto social necesario para el desarrollo del capitalismo nacional, y finalmente se hace una retrospectiva histórica de la entelequia del ser 
YANNET PAZ-CALDERÓN, MARÍA HERLINDA SuÁREZ-ZOZAYA, MÓNICA TERESA ESPINOSA-ESPÍNDOLA

joven en el contexto de las profundas transformaciones estructurales que se gestaron con la implementación y desarrollo del capitalismo en el país. El punto de partida se ubica entre la Reforma y la Revolución mexicana, periodo en el que se sentaron las bases de grandes cambios políticos, sociales y económicos que dieron lugar a la construcción del sujeto joven, el cual surgió como parte de las exigencias del proceso de consolidación del sistema capitalista.

\section{El México moderno de corte capitalista}

La instauración del capitalismo en México tuvo lugar en la segunda mitad del siglo XIX,, época en la que comenzó a imperar una política de crecimiento liberal auspiciada por la burguesía, después del triunfo republicano sobre Francia y los conservadores en 1867. Siguió una etapa de reformas liberales que permitieron la consolidación de diversas libertades económicas, sociales y políticas, lo que dio como resultado un período de reactivación económica auspiciada por la proliferación de modernas industrias textiles. El perfeccionamiento de los derechos de propiedad iniciado en esta etapa condujo a la conformación de un Estado promotor del desarrollo capitalista (Ramírez, 2012; Kuntz, 2010). Este Estado liberal tuvo como objetivo formar una nación homogénea en la que todos los individuos fueran ciudadanos libres e iguales; es decir, se eliminó a través de las leyes toda diversidad y heterogeneidad. La unificación del país estuvo basada en el establecimiento de un solo sistema educativo, económico, jurídico y administrativo. Es evidente que esto constituyó un grave problema, al construirse una nación sobre el no reconocimiento de la diversidad cultural, económica y social de muchos pueblos y comunidades (Ornelas, 2005).

Los primeros cambios institucionales que dieron pie a un nuevo marco jurídico sobre el cual se desarrolló la actividad económica comenzaron en 1856 con la Ley de Desamortización, que tenía como objetivo individualizar las propiedades pertenecientes a las corporaciones civiles y eclesiásticas. En 1883 se promulgó la Ley sobre Colonización y Compañías
Deslindadoras, que permitía el uso de terrenos baldíos, los deslindes y la colonización de tierras campesinas; a las empresas que realizaban esta actividad les correspondía la tercera parte de la superficie deslindada como recompensa por los gastos en los que incurrían, lo que provocó pleitos, despojos e incertidumbre. La minería también fue sujeta a modificaciones que permitieron nuevas explotaciones, para lo cual se establecieron leyes y códigos que garantizaron los derechos de propiedad y la continuidad de los mismos. Por otro lado, en la Constitución de 1857 se estableció la libertad de ocupación, se prohibía el trabajo bajo algún tipo de coacción, y se instituyó la inviolabilidad de la propiedad privada, elementos que permitieron disponer de fuerza de trabajo libre (Ornelas, 2005; Kuntz, 2010).

Estas medidas favorecieron la formación de la burguesía nacional, que desde mediados del siglo XIX había comenzado a constituirse, principalmente por prestamistas, comerciantes y hacendados que lograron acumular cantidades importantes de capital, y también por algunos extranjeros. Si bien se invirtió capital en los sectores agrícola, minero y textil, este último fue el de mayor relevancia y constituyó el eje de la industrialización. Las fábricas textiles de lana y algodón fueron las predominantes en esa época, y en ellas se utilizaban para la producción maquinaria y técnicas modernas (Ramírez, 2012). El auge de esta industria permitió una expansión de las relaciones capitalistas de producción; es decir, la dinámica económica producida por la actividad textil hizo posible que se fueran vislumbrando de manera más clara dos clases sociales: por un lado, los trabajadores asalariados $y$, por otro, los dueños de las empresas, quienes serían los que acumularían la riqueza.

Estos cambios fueron acompañados por transformaciones legales y económicas que permitieron pasar de una organización productiva tradicional, a una cuya base fue la utilización eficiente de los recursos naturales, lo que conllevó diversas implicaciones, entre ellas, sustanciales cambios en las relaciones sociales de producción. Marx (1986) indica que una condición necesaria para que el capital 
YANNET PAZ-CALDERÓN, MARÍA HERLINDA SUÁREZ-ZOZAYA, MÓNICA TERESA ESPINOSA-ESPÍNDOLA

surja es que "legalmente" se dé una separación entre el poseedor de los medios de producción y el dueño de la fuerza de trabajo, y, además, que este último tenga como única forma de subsistencia vender su capacidad de trabajar. Cuando la fuerza de trabajo se vuelve una mercancía como cualquier otra, tanto compradores como vendedores se encuentran en el mercado como personas "jurídicamente iguales", es decir, lo que se compra es la habilidad de trabajar de la persona. Para que el dinero, las mercancías o los medios de producción puedan convertirse en capital, debe ocurrir lo siguiente:

[...] han de enfrentarse y entrar en contacto dos clases muy diversas de poseedores de mercancías; de una parte, los propietarios de dinero, medios de producción y artículos de consumo, deseosos de valorizar la suma de valor de su propiedad mediante la compra de fuerza ajena de trabajo; de otra parte, los obreros libres, vendedores de su propia fuerza de trabajo [...] Obreros libres, en el doble sentido de que no figuran directamente entre los medios de producción, como los esclavos, los siervos, etc., ni cuentan tampoco con medios de producción propios, como el labrador que trabaja su propia tierra, etc. [...] Con esta polarización del mercado de mercancías, se dan las dos condiciones fundamentales de la producción capitalista...La llamada acumulación originaria no es, pues, más que el proceso histórico de disociación entre el productor y los medios de producción (Marx, 1986: 608).

Las nuevas relaciones de producción no son obra de la casualidad, sino que surgen del mismo proceso de producción que está en marcha y que entra en contradicción con las relaciones de producción precedentes (Marx, 1985). En el caso de México, como ocurrió en otras partes del mundo que transitaron de un modo de producción tradicional a uno capitalista, estos cambios se produjeron en las estructuras legal, económica y política del país.

\section{LA CONSTRUCCIÓN HISTÓRICA DEL SUJETO JOVEN EN MÉXICO}

\section{La educación y el trabajo asalariado como precursores en la construcción del sujeto joven}

A mediados del siglo XIX ocurrieron diversos cambios institucionales y legales en la economía mexicana, los cuales estuvieron encaminados a establecer las bases que se requerían para la implementación del capitalismo en el país. En aquella época aún prevalecían muchas formas de explotación feudales en las que el trabajo presentaba modalidades como la esclavitud, la aparcería y el aprendizaje en talleres; además, el acceso a los gremios sólo era posible por privilegios tradicionales. En estas circunstancias, ni la edad ni el sexo representaban elementos importantes para apoyar en el trabajo familiar porque las personas pasaban directamente de ser niños a adultos.

Sin embargo, el capitalismo exigía de la sociedad donde se implantaba ciudadanos que se adaptaran a la dinámica de su modo de producción. Necesitaba individuos que fueran "capitalistas" o, en otras palabras, que tuvieran habilidades y conocimientos para la correcta administración del capital y de la nueva empresa. Estos eran por lo común los hijos de las familias de clases altas, quienes tenían la posibilidad de prepararse durante más tiempo y acceder a una mejor educación. Dobb señala que en sus inicios el capitalismo requirió de:

[...] un nuevo tipo de capitalista, ya no simplemente como usurero o comerciante en su oficina o almacén, sino como capitán de industria, organizador y planificador de las operaciones de la unidad de producción, que ponía en vigor una disciplina autoritaria sobre un ejército de trabajadores que, despojados de la ciudadanía económica, debían ser compelidos a desempeñar sus duras obligaciones al servicio de oro bajo el látigo del hambre, unas veces y, otras bajo el del contramaestre (Dobb, 1999: 310-311).

Pero también necesitaba individuos que realizaran el trabajo en las fábricas. Estas personas, si bien no destinaban tiempo a su preparación formal, o destinaban menos tiempo y menos conocimientos que los nacidos 
en familias ricas, sí era importante que recibieran preparación para el trabajo asalariado. Algunos, como se verá más adelante, tenían la oportunidad de aprender algún oficio en escuelas determinadas para ese fin, y otros, menos favorecidos, pasaban directamente a trabajar en las fábricas.

Esta separación entre dos grupos de individuos fue resultadodelas necesidades que el sistema de producción capitalista precisaba para su funcionamiento, y fue a través del mercado de trabajo como los ciudadanos pudieron encontrar espacios en la esfera productiva. Es decir, fue necesaria la construcción, por medio de leyes y reglamentos, de un mercado laboral constituido por: oferentes - campesinos despojados de sus tierras que necesitaban trabajar para sobrevivir-y demandantes —dueños de tierras, fábricas de textiles y minerías - de fuerza de trabajo. Los primeros, al tener la necesidad de sobrevivir y no contar con algún medio de producción, tuvieron que vender su capacidad de trabajo. La creación de este mercado de trabajo constituyó un elemento clave en el desarrollo del capitalismo nacional.

Fue así como a partir de mediados del siglo XIX en México se produjeron transformaciones importantes en la familia, el trabajo, la educación y el ejército, cambios que impactaron en la condición de la población. Es en ese momento histórico cuando se puede establecer la génesis del "sujeto joven” en México. Diversos autores coinciden en que una primera aproximación a lo que ahora se conoce como juventud se puede ubicar entre la época de la Reforma y el Porfiriato, en el último cuarto del siglo XIX, cuando se puede identificar a unos no niños, no adultos, principalmente en las familias ricas (Urteaga, 2011).

El periodo de Reforma constituyó un esfuerzo por hacer de México una nación liberal, por lo que se buscó educar al pueblo, y primordialmente formar a su juventud. Entre 1880 y 1920 en el país se comenzaron a perfilar, al mismo tiempo, los conceptos modernos de infancia y juventud, y la identificación de ambos grupos formó parte de un mismo proceso, porque los individuos se comenzaron a clasificar por la edad con el fin de poder prepararlos como fuerza de trabajo con las características que el capitalismo necesitaba. De manera simultánea, el reconocimiento de los derechos y de la protección que debían tener los infantes surgió a finales del siglo XIX y se reforzó en el primer tercio del siglo XX (Sosenki, 2010).

En la segunda mitad del siglo XIX y las primeras décadas del siglo XX una prioridad fue formar trabajadores, y las políticas educativas se encaminaron a ese fin, ya que era útil para la vida social enseñar artes y oficios a los hijos de las familias pobres; por tal motivo, se estableció formalmente la educación básica a través de la Ley de Educación Primaria de 1908. En general, los gobiernos posrevolucionarios buscaron empatar el trabajo de estos niños con la educación para el empleo ${ }^{2}$ (Guerrero, 2007; Sosenki, 2010; Urteaga, 2011).

En México, como en otras naciones, la juventud surgió, como concepto, ligada a los cambios que se produjeron entre 1870 y 1925 en el sistema educativo, cuando se crearon los períodos educativos de secundaria y preparatoria, y se definió la edad escolar hasta los 18 años. Los gobiernos liberales y posrevolucionarios incentivaron un tipo de educación positivista que sirviera de base a la nueva mentalidad que debía tener la población, alineada al orden y la libertad económicos, lo que se tendría que traducir en una "buena conducta en el trabajo". Éste era el objetivo que en realidad se buscaba al introducir en las instituciones escolares a los niños y jóvenes, principalmente a los de clases populares: “[...] los jóvenes que accedían a la educación preparatoria a los 13 años y terminaban sus estudios a los 15, edad en la que optaban por empezar a trabajar o continuar con alguna profesión" (Urteaga, 2011: 56). La escuela se erigió, a partir de entonces, como una institución de suma importancia en el proceso de educación de los jóvenes, donde se transmiten conocimientos, habilidades, y el discurso dominante con respecto a lo que se espera sea ese el individuo: emprendedor, disciplinado, responsable y competitivo. Es decir, el nuevo sistema educativo respondió a una nueva necesidad del capitalismo: formar trabajadores con determinadas habilidades y conocimientos, para un mercado de trabajo que era "el vocero" de lo que la industria requería en términos laborales; en este mercado, se pasó de permitir la libre entrada a todo 
aquel que tuviera necesidad de trabajar, a clasificar a esos oferentes de trabajo de acuerdo con sus capacidades y habilidades productivas.

En la posrevolución, el trabajo infantil y la instrucción constituyeron un binomio natural; se buscó que esos pequeños trabajadores se convirtieran en los obreros sanos y capacitados que el capitalismo nacional necesitaría a medida que avanzara en su desarrollo, es decir, serían los trabajadores del mañana. En el discurso de la modernización capitalista que imperaba en el país en la segunda década del siglo XX, durante la presidencia de Plutarco Elías Calles, la formación humanística promovida por Vasconcelos fue reemplazada por una perspectiva productivista, industrializadora e higienista:

Las escuelas de carácter técnico e industrial, las vocacionales, las correccionales de artes y oficios, enseñarían un modo decoroso de ganarse la vida [...] La labor de la escuela era infundir hábitos de trabajo y estudio, valores de orden, disciplina, obediencia, subordinación, competencia, ahorro y puntualidad (Sosenki, 2010: 232).

El requisito para ingresar a estas escuelas técnicas o industriales era haber terminado la primaria o ser mayor de 14 años; al terminar el aprendizaje en ellas, recibían un título de obreros. Cabe mencionar que quienes asistían a estas instituciones educativas tenían cierto tiempo libre y sus familiares podían sufragar los gastos que esta educación implicaba (Sosenki, 2010). Los hijos de familias pobres tenían pocas posibilidades de asistir a estas escuelas, y si lo hacían era por un período corto porque la necesidad les obligaba a trabajar de tiempo completo. La disciplina, el orden y el amor al trabajo fueron los principales valores transmitidos. En la década de 1920, en el discurso del Estado se fomentaba la figura de un joven con espíritu de renovación y justicia, capaz de dirigir la sociedad posrevolucionaria. Los discursos desde diferentes ámbitos sociales construyeron e impusieron conocimientos, hábitos, valores, sentimientos e imágenes que definían las maneras adecuadas y deseables de ser un joven moderno y citadino (Urteaga, 2011). Estos jóvenes eran el futuro del país.

Al finalizar la etapa armada de la Revolución mexicana, los gobiernos posteriores a esta época se dieron a la tarea de iniciar un proceso de modernización en el país que era necesario para afrontar las exigencias del sistema capitalista que estaba surgiendo. Para ello, fue necesario crear no sólo nuevas condiciones materiales, como infraestructura, sino también políticas y sociales. Asimismo, fue imperativo configurar a los nuevos individuos, que se adaptarían y servirían al proceso de industrialización nacional. La instauración del capitalismo se apoyó, entonces, en la construcción de un marco laboral, jurídico y educativo que permitió al Estado transmitir e imponer la ideología liberal a la sociedad, enalteciendo los beneficios que este sistema económico traería para todas las clases sociales.

En esta nueva dinámica productiva nacional, que se dinamizó en la época posrevolucionaria, era necesario contar con un tipo de ciudadano - mestizo - cuyo "perfil social combinaba rasgos del proletariado obrero y campesino, y de la clase media [...] trabajador honesto y buen padre de familia. Ideológicamente, era portador del patriotismo y fungía como un agente activo en la difusión y la profundización del nacionalismo de Estado" (Urías, 2017). Para lograr este cometido fue necesario inculcar en la población pobre el apego al trabajo y a la educación, el amor a la patria y al orden civilizado (Guerrero, 2007).

La reorganización nacional posrevolucionaria requería de nuevas políticas e instituciones que ayudaran a controlar a cada sector de la población y a colocarlo en el "lugar que le correspondía" en el marco de los procesos de producción capitalista. Entre la primera y la tercera décadas del siglo XX, el sistema educativo quedó así subordinado al modelo capitalista. Entonces las escuelas, dirigidas a capacitar para el trabajo, fomentaron, por un lado, la creación de mano de obra barata y calificada y, por otro, la formación de ciudadanos con valores.

Las escuelas para el trabajo y la capacitación laboral escolar impulsaron, por un lado, la formación de 
mano de obra barata y calificada que incrementara la producción, y por otro lado la creación de ciudadanos con valores revolucionarios [...] Hasta 1934 la educación estuvo lejos de sembrar ideas de igualdad, más bien enfatizó diferencias sociales y reforzó distinciones, tanto de clase como de género (Sosenki, 2010: 262).

La transformación productiva que se inició en México desde mediados del siglo XIX provocó muchos cambios que trastocaron la vida cotidiana de las familias; en este contexto, como se mencionó líneas arriba, la gestación del sujeto joven estaba encaminándose hacia dos vertientes:

1. La formación de los sujetos jóvenes trabajadores. La juventud se relacionó con una etapa de moratoria, lo que implicaba que los jóvenes debían pasar por un período de aprendizajes y de preparación que les permitiría alcanzar la madurez necesaria para ser considerados adultos. En las clases populares estos jóvenes se preparaban para la adultez desde el trabajo; sólo algunas familias tenían posibilidades de enviar a los niños a la escuela para cursar el nivel básico, donde aprendían a leer y a escribir. Los jóvenes pobres que se incorporaban a temprana edad al mercado de trabajo no eran considerados adultos hasta que lograban ser independientes y formar una familia.

2. El otro tipo de joven que se buscó construir fue el estudiante. La creación de la universidad no fue suficiente para lograr este objetivo; serían los "gobiernos posrevolucionarios que intentaron establecer un puente generacional para trascender su proyecto político al futuro a través de un cambio ideológico en la enseñanza, los que impulsaron un espacio político para el surgimiento de este sujeto" (Urteaga, 2011: 73). Y para evitar la rebeldía y conductas peligrosas y delictivas se crearon espacios deportivos y culturales; la imagen de este sector era la de un joven de clase alta o media, deportista, educado e integrado.
El capitalismo creó un discurso que enaltecía el trabajo individual no sólo como un medio - necesario - para sobrevivir, también como un instrumento de superación para hombres, mujeres, jóvenes y niños. Desde las esferas del poder comúnmente se han destacado los beneficios de tener un empleo, bajo el argumento de que es a través del trabajo como disminuirán la miseria, la mendicidad e incluso la delincuencia de la población más desprotegida. Por lo tanto, ofrecer capacitación a los hijos de las familias pobres era algo que debía agradecerse. En el capitalismo, el trabajo fue así implantándose como un valor universal, y este discurso oficial sirvió para encubrir la explotación a la que los obreros, de todas las edades y de ambos sexos, fueron sometidos. Fue así como comenzó a perfilarse el sujeto joven, de acuerdo con las necesidades que el capitalismo nacional marcaba con respecto a la disponibilidad de fuerza de trabajo calificada y no calificada. Esto obligó a que la preparación para el trabajo de los individuos comenzara desde la niñez. En el impulso que se dio a la educación se pueden identificar las características que se esperaba que tuvieran los jóvenes:

a. A los niños se les impuso cumplir con cierto número de años de escolaridad básica, y de ahí pasar a una formación para el trabajo con el objetivo de que adquirieran determinados conocimientos y habilidades; esto sucedía cuando los niños dejaban la etapa infantil y pasaban al período de juventud.

b. Con el establecimiento del proceso educativo por el que debían transitar los niños y los jóvenes, se comenzó a establecer un período de moratoria o de preparación, es decir, un tiempo de espera para poder entrar al mundo adulto. Cierto es que este período de prórroga se vivía de diferente forma dependiendo de la clase social a la que pertenecieran los jóvenes; por ejemplo, para los hijos de las familias burguesas o acomodadas este aplazamiento constituyó un privilegio porque su entrada al mundo adulto podía esperar varios años mientras terminaban alguna preparación profesional, de modo que el horizonte de aspiraciones de estos jóvenes era más amplio. 
c. Las familias pobres también adoptaron este periodo de moratoria para sus hijos, pero de forma diferente; también eran asumidos como sujetos que necesitaban prepararse para ser responsables, independientes y formar una familia, aunque en estos grupos sociales la escuela no era indispensable para conseguir lo que se esperaba de ellos. El tiempo de espera para la incorporación social de los jóvenes de bajos recursos se vivía de diferente forma, porque ellos pasaban el tiempo de formación en el mercado de trabajo — formal e informal-, adquirían experiencia y habilidades en ese espacio, y sólo después de cierta edad eran considerados adultos. Los parámetros de adultez para ellos consistían en tener un oficio y ser jefes de familia, y la única prorroga de la que disponían era el tiempo que tardaban en encontrarse en esa situación de independencia. Los jóvenes aprendices de oficios eran hijos de campesinos, artesanos o migrantes, y su vida activa comenzaba a los diez años, cuando ingresaban a la casa de un maestro —de oficio-, o entraban a alguna hacienda como sirvientes; cuando tenían 15 años podían comenzar su vida independiente (Urteaga, 2011).

d. El ámbito jurídico penal también ayudó a ir dibujando la imagen de los sujetos jóvenes, sobre todo a aquellos que eran estigmatizados como delincuentes, a los que quedaban fuera de las esferas o instituciones sociales establecidas o a los que se revelaban en contra de las normas. Respecto a los menores de edad que habían cometido un delito, el Código Penal de 1871 estipulaba la liberación de los menores de 9 años de todo cargo penal, y ubicaba en una situación dudosa a aquellos que se encontraban entre los 9 y los 14 años. Los que tenían entre 14 y 18 años eran considerados responsables, pero con penas mínimas. La mayoría de edad penal se estableció en los 18 años. En 1883 se introdujo una reforma al código en la que se explicitaba que el Estado debía fomentar la educación de los jóvenes en profesiones acordes al proyecto liberal de nación, así como su participación en el trabajo, y se les concedía la mayoría de edad entre los 18 y los 20 años. La pubertad comenzaba a los 14 años para los varones y a los 12 para las mujeres, y para ambos géneros se daba por concluida a los 21 años; antes de esta edad necesitaban el permiso de los padres para contraer matrimonio. Se les otorgó la ciudadanía a los 21 años, a los 18 si estaban casados, y a las mujeres se les restringió el derecho a votar (Urteaga, 2011; Sosenki, 2010).

Entre mediados de siglo XIX y las primeras décadas del XX se produjo una doble construcción del sujeto joven; por un lado, se intentó instruir a los niños pobres para que fueran los futuros trabajadores que el sistema productivo necesitaba y, por otro lado, se estaba formando la clase estudiantil, constituida por hijos de familias de clase media y alta, que serían los encargados de administrar las empresas y de reproducir los ideales capitalistas. La expansión de las relaciones capitalistas de producción desencadenó un extenso proceso de edificación productiva y social, de modo que los sectores público y privado tuvieron que comenzar a formar a la población, en especial a las generaciones jóvenes, en las habilidades y características determinadas que requerían las empresas. El Estado estableció leyes e instituciones encargadas de educar a la población, que a su vez necesitaba adecuarse a los cambios técnicos y científicos que se estaban produciendo en el ámbito industrial. Las políticas educativas fueron decisivas para integrar y delimitar un grupo específico - y modernode población, que fueron los jóvenes trabajadores.

\section{Y los jóvenes, ¿cómo reaccionan ante lo establecido?}

Los sujetos sociales que el sistema de producción comienza a dibujar o construir aparecen impregnados de características y formas de ser y actuar que están influidas de las condiciones de la clase social de la cual emergen, y comienzan a responden ante lo que social y económicamente se les exige o se les impone. Pérez 
YANNET PAZ-CALDERÓN, MARÍA HERLINDA SUÁREZ-ZOZAYA, MÓNICA TERESA ESPINOSA-ESPÍNDOLA
(2004) indica que la escuela, la fábrica y el ejército, a través de sus mecanismo de poder y disciplinamiento, provocaron: a) el surgimiento de códigos que permiten la identificación de los jóvenes entre sí, b) la posibilidad de vincularse para resistirse a lo impuesto por el sistema, e incluso para combatirlo, y c) la existencia de grupos juveniles que quedan al margen de las instituciones, y llegan a estar estigmatizados, de tal manera que son tratados y perseguidos como delincuentes, por lo que se busca recluirlos en prisiones o centros de readaptación social. A medida que los jóvenes se fueron constituyendo como un grupo poblacional y fueron identificados así, adquirieron mayor protagonismo social, cultural e incluso político.

El carácter contestatario que se fue formando en los jóvenes provocó que poco a poco se definieran en el imaginario social estereotipos de estigmatización hacia ellos. Por ejemplo, principalmente a los jóvenes de sectores pobres se les relacionaba con la delincuencia o con la realización de actividades al margen de la ley porque se los consideraba de naturaleza rebelde. Se llegó a temer a estos jóvenes porque tenían rasgos de libertinaje, vagabundeo y turbulencia, pero lo cierto es que muchos se revelaban a ese destino que el capitalismo les imponía: el trabajo asalariado, por lo que se consideraba necesario controlarlos. Esta situación permitió justificar que se buscara, a través de la educación, la familia y el Estado, la formación de trabajadores "respetables", y sobre todo "resignados", porque el trabajo, sin importar sus condiciones, se presentó como la única opción para apartar a estos jóvenes de posibles actividades delictivas.

Desde las primeras décadas del siglo XX comenzaron a perfilarse las primeras imágenes simbólicas de jóvenes, que fueron producto de los cambios en su conducta derivados de su carácter rebelde, contestatario y de su búsqueda de identidad y autonomía. El sujeto joven, a medida que se fue construyendo, también fue tomando conciencia del rol que se exigía dentro del sistema productivo y social, y fue buscando maneras de manifestarse ante las normas y reglas que se le imponían. Es importante señalar que, en la construcción de estas primeras imágenes simbólicas de los jóvenes, la prensa desempeñó un papel crucial con diversas publicaciones en sus secciones de sucesos policiacos (Levi y Schmitt, 1996).

La primera figura era la del muchacho que se resistía a ejercer la actividad de aprendiz, se escapaba de su patrón y se dedicaba a andar por las calles vagabundeando, delinquiendo; era el pilluelo de las grandes ciudades, aquel que no tenía ni familia ni casa ni trabajo fijo, que realizaba diferentes actividades de día y de noche, repartiendo publicidad, ayudando a los viajeros que llegaban de las diligencias, cargando bultos, etcétera. La segunda era la figura del obrero urbano, que pertenecía a alguna pandilla que llevaba el nombre del barrio donde vivía, que le incomodaba la fábrica y el trabajo asalariado y le agradaba deambular por las avenidas con amigos y chicas (Levi y Schmitt, 1996; Guerrero, 2007; Sosenki, 2010). En cuando a las mujeres jóvenes pobres, el mercado de trabajo para ellas era reducido. Principalmente trabajaban en la industria textil y de confección y en el servicio doméstico; ${ }^{3}$ también vendían en los mercados o se contrataban como lavanderas o niñeras. A lo largo del siglo XIX las jóvenes obreras siguieron acumulando desventajas económicas y sociales debido a su condición de género, y para ellas fue difícil encontrar espacios laborales diferentes a los que tradicionalmente se les asignaban (Scott, 1993; Levi y Schmitt, 1996). En la esfera doméstica remunerada, como en muchas donde trabajan menores, existe una significativa flexibilidad; las mujeres podían ser mandaderas, lavanderas, nanas, cocineras, sirvientas, en fin, podían realizar las actividades que se requerían en el mantenimiento de una casa, y sólo en contados casos los patrones tenían cierta consideración hacia estas trabajadoras, más bien la mayoría sufría abusos graves, desde regaños y golpes, hasta violaciones. El servicio doméstico era de los más desprotegidos y vulnerables porque estaba fuera de la vista de las autoridades, por lo que había pocos intentos por mejorar la situación de niñas y mujeres jóvenes.

La tercera figura corresponde a los jóvenes varones de clases medias y altas, quienes eran educados por sus padres para tener amor al trabajo y buscar el éxito, la popularidad e influencias, mientras las jóvenes eran 
YANNET PAZ-CALDERÓN, MARÍA HERLINDA SUÁREZ-ZoZAYA, MÓNICA TERESA ESPINOSA-ESPÍNDOLA

preparadas para ser modestas, obedientes, piadosas y buenas amas de casa. José Tomás Cuellar escribió en 1871 la novela Ensalada de pollos y baile de cochino, en la que hace un retrato interesante de los jóvenes urbanos pertenecientes a las clases sociales acomodadas de finales del siglo XIX (Urteaga, 2011).

Feixa (1999) sostiene que son cinco las condiciones que permitieron que el joven como sujeto social apareciera como actor protagonista de la escena pública del siglo XX. ${ }^{4} \mathrm{El}$ primero fue el nacimiento del llamado "Estado de bienestar", en el marco del cual se necesitaban datos y estadísticas de la población a la que se dirigirían las distintas políticas — principalmente las sociales-; para ello fueron creadas instituciones y reglamentaciones destinadas a la protección y asistencia de diferentes grupos de personas, entre ellos los jóvenes. La segunda condición fue la crisis de la autoridad patriarcal, que permitió a los jóvenes mayor libertad; de hecho, el autor señala que se produjo una revuelta contra toda forma de autoridad. En tercer lugar, se produjo la formación de un mercado de productos como música, revistas o moda, destinados a los jóvenes con poder adquisitivo. El auge de los medios de comunicación masivos, que hizo posible la creación de una cultura juvenil internacional, fue el cuarto rasgo, porque a través de estos medios los jóvenes pudieron identificarse más con sus coetáneos. Y, por último, la modernización permitió una transformación de la moral puritana por otra más consumista y relajada; un resultado de ello fue la "revolución sexual", la cual fue posible, entre otros factores, por la difusión de los anticonceptivos.

\section{La juventud: una invención del capitalismo}

En este documento se ha puesto énfasis en esta idea, es decir que la juventud surge como una necesidad o exigencia productiva del sistema capitalista. Lo primero que se debe reconocer al hablar de juventud es que ésta no es una condición que se encuentre en las personas de manera natural. Este concepto, con el que ahora se identifica a un sector de la población con características propias, es una construcción sociohistórica que surge como resultado de un inédito orden productivo en
Occidente, que comenzó a exigir individuos con determinados conocimientos y habilidades para contribuir al florecimiento de una sociedad muy distinta a la feudal, y de una clase social que emergió junto con el sistema de producción: la burguesía. Marx indica que:

En la producción social de su existencia, los hombres establecen determinadas relaciones necesarias e independientes de su voluntad, relaciones de producción, que corresponden a un determinado estadio evolutivo de sus fuerzas productivas materiales. La totalidad de esas relaciones de producción constituyen la estructura económica de la sociedad, la base real sobre la que se alza un edificio jurídico y político, al cual corresponden determinadas formas de conciencia social (Marx, 2009: 66).

En necesario señalar que en todo este proceso de separar a las familias de los medios de producción, el Estado, como señala Kaplan (1993), jugó un papel importante a través de las distintas tareas y propósitos que fue asumiendo — desde su período final absolutista hasta su posterior etapa liberal-, entre las que destacan: a) la eliminación de todo tipo precapitalista de dominación y producción - agricultura campesina tradicional, y en general ocupaciones consideradas arcaicas-; b) la creación, por medio de leyes, de mercados libres de trabajo, de capitales y de tierra; c) el reconocimiento de las diversas formas de concentración y centralización del capital, principalmente en lo que se refería a los requerimientos de control, financiamiento y tecnología; y d) la creación de una economía monetaria y mercantil.

Fue así como, con el desarrollo de las fuerzas productivas, los poderes públicos y privados fomentaron una formación para los jóvenes encaminada, en primer lugar, al conocimiento de nuevas tecnologías y, en segundo lugar, a la creación de individuos disciplinados y trabajadores; es decir, modelaron un sujeto social al servicio del capitalismo industrial. En este sentido, la juventud es una invención y una exigencia de la sociedad industrial.

Con la modernización los jóvenes se vieron cada vez más expuestos a diferentes tipos y niveles de 
influencias, de modo que la familia y la comunidad ya no constituían los únicos factores de socialización. La regulación del mercado de trabajo, la implementación de la educación obligatoria, el servicio militar y el derecho al voto permitieron también el desarrollo de la juventud como grupo social. La educación poco a poco se hizo importante no sólo para ingresar al mercado laboral, también para tener una iniciación y un reconocimiento social.

La juventud, al ser identificada como un sector de población que necesitaba ser formado, moldeado y protegido para tener un tránsito exitoso a la adultez, permitió que en torno a ella se formaran estereotipos pocas veces favorables.

\section{Reflexiones finales}

El tema de la juventud, visto desde su historicidad o desde su proceso arqueológico, puede analizarse a través de los ciclos del capitalismo, proceso que resulta útil para comprender la manera en que se configuró al sujeto joven. La juventud ha sido concebida como una etapa en la que los individuos se encontraban en un momento de preparación y formación, para posteriormente pasar a la vida adulta, cuando podrían tener un trabajo y una familia propia. Dentro de esta lógica, ser joven o estar en este grupo etario tenía que ver más que con una condición biológica, con un rol socialmente creado y asignado. Como se mencionó a lo largo del texto, este "ser o actuar como joven" surgió como una construcción propia de la sociedad moderna industrial.

Es importante que, al abordar el análisis de los jóvenes o de la juventud, en primer lugar se ubique al sujeto concreto - considerando género, escolaridad, región de pertenencia, cultura, etcétera-, dentro de un contexto específico ligado a la totalidad socioeconómica y cultural. En segundo lugar, debe tomarse en cuenta que las características y el comportamiento de los jóvenes están impregnados por las necesidades capitalistas de producción y de consumo. Por estas razones, no se puede considerar que exista una sola manera de ser joven, porque en este grupo existe gran diversidad y complejidad, características marcadas no sólo por las variables sociodemográficas, sino por la manera en cómo la organización social y productiva los valora, principalmente a través del mercado de trabajo. Además, su comportamiento también se ve influenciado por el contexto material, social y cultural en el cual se desenvuelven.

En este documento se plantearon reflexiones en torno a la edificación histórica del sujeto joven en México, cuya génesis se ubica dentro del proceso de implementación del capitalismo en el país.

\section{Notas}

${ }^{1}$ Hasta la primera mitad del siglo XIX, en la economía mexicana seguían presentes características de un régimen productivo antiguo, caracterizado por el predominio de la actividad agrícola sujeta a los ciclos de lluvia naturales; además, las necesidades de pueblos y ciudades eran satisfechas con productos derivados del trabajo artesanal. La industria textil de algodón era la principal actividad en este sector, pero su dinamismo era bastante limitado (Kuntz, 2010).

2 En la época posrevolucionaria el Estado se convirtió en el poder central de la nación, encargado de organizar la actividad económica, social y política que estaba encaminada a construir el concepto de soberanía, lo que implicó diseñar el civismo de la población, así como símbolos patrios y hechos históricos con los que contribuyó a someter la voluntad ciudadana, por lo que se constituyó un partido único de Estado. Por ejemplo, el Estado controló varios aspectos, sino es que todos, relacionados con la actividad laboral, y decidió, entre otros factores, sobre la existencia o no de sindicatos y el derecho a huelga (Ornelas, 2005).

${ }^{3}$ Scott (1993), apunta que, en casi todos los países en vías de industrialización, el servicio doméstico era la actividad que más mujeres empleaba, superando por mucho al sector textil. En 185l, en Inglaterra el 40\% de las mujeres que trabajaban lo hacían como empleadas domésticas, y sólo el 22\% trabajaban en las fábricas textiles.

4 "La historia del siglo XX puede verse como la sucesión de diferentes generaciones de jóvenes que irrumpen en la escena pública para ser protagonistas en la reforma, la 
YANNET PAZ-CALDERÓN, MARÍA HERLINDA SUÁREZ-ZOZAYA, MÓNICA TERESA ESPINOSA-ESPÍNDOLA

revolución, la guerra, la paz, el rock, el amor, las drogas, la globalización o la antiglobalización" (Feixa, 2006: 3).

\section{Referencias}

Balardini, Sergio (2000). "De los jóvenes, la juventud y las políticas de juventud”. En Última Década, 13: 11-24. Valparaíso: CIDPA.

Dávila, Oscar (2004). "Adolescencia y juventud: de las nociones a los Abordajes”. En Última Década, 21: 84104. Valparaíso: CIDPA.

De la Peña, Sergio (1999). La formación del capitalismo en México. México: Siglo XXI.

Dobb, Maurice (1999). Estudios sobre el desarrollo del capitalismo. México: Siglo XXI.

Erazo, Edgar (2009). "De la construcción histórica de la condición juvenil a su transformación contemporánea". En Revista Latinoamericana de Ciencias Sociales Niñez y Juventud, 7(2): 1303-1329.

Feixa, Carles (2006). "Generación XX. Teorías sobre la juventud en la era contemporánea”. En Revista Latinoamericana de Ciencias Sociales, Niñez y Juventud, 4(2): 1-18.

Feixa, Carles (1999). De jóvenes, bandas y tribus. Antropología de la juventud. Barcelona: Ariel.

Guerrero, David (2007). "Valoración del trabajo infantil en México 1910-1920”. En Alicia Mayer (coord.), México en tres momentos: 1810-1910-2010. Hacia la conmemoración del bicentenario de la independencia y el centenario de la Revolución mexicana, retos y perspectivas. México: Instituciones de Investigaciones Históricas-UNAM.

Kaplan, Marcos (1993). Revolución tecnológica, estado y derecho. Ciencia, estado y derecho en las primeras revoluciones industriales, t. I, serie E, núm. 56. México: Instituto de Investigaciones Jurídicas-UNAM.

Kuntz, Susana (2010). "De las grandes reformas liberales a la gran depresión, 1856-1929". En Sandra Kuntz (coord.), Historia económica general de México: de la Colonia a nuestros días. México: El Colegio de México, Secretaría de Economía.

Levi, Giovanni y Jean-Claude Schmitt (1996). Historia de los jóvenes. De la antigüedad a la Edad Moderna. España: Taurus.
Marcial, Rogelio (2012). "Políticas públicas de juventud en México: discursos, acciones e instituciones". En Revista Ixaya, II(3): 9-49. Guadalajara, México: Universidad de Guadalajara.

Marx, Carlos (1985). El capital, Teoría, estructura y método. El método de la economía política. México: Ediciones de Cultura Popular.

Marx, Carlos (1986). El capital. Crítica de la economía política, t. 1. México: Fondo de Cultura Económica.

Marx, Carlos (2009). El capital. Introducción general a la crítica de la economía política/1857, t. I. México: Siglo XXI.

Ornelas, Jaime (2005). El siglo $\chi \chi X$ mexicano: economía y sociedad. Puebla: Dirección General de Fomento Editorial.

Paz, Yannet, Herlinda Suárez y Guillermo Campos (2016). "El papel del trabajo en la construcción del sujeto joven". En Revista Latinoamericana de Ciencias Sociales, Niñezy Juventud, 14(2), julio-diciembre: 1303-1311.

Paz, Yannet y Guillermo Campos (2012). "La imposibilidad de una juventud en éxtasis: la exclusión laboral y educativa en México". En Tecsistecatl, 4(13): 2-3.

Pérez, José A. (2004). "Historizar a los jóvenes". En J.A. Pérez Islas y Maritza Urteaga Castro-Pozo (coords.), Historia de los jóvenes en México. Su presencia en el siglo XX. México: SEP-IMJ, AGN, pp. 17-32.

Ramírez, Estela (2012). "El desarrollo del capitalismo en México en la segunda mitad del siglo XIX". En Economía Informal, 374, mayo-junio: 26-52. México: Facultad de Economía-UNAM.

Scott, Joan (1993). "La mujer trabajadora en el siglo XIX". En George Duby y Michelle Perrot (coords.), Historia de las mujeres en el Occidente, vol. 4, Fraisse Geneviève y Michelle Perrot (coords.), El siglo XIX. España: Santillana. pp. 405-436.

Sosenki, Susana (2010). Niños en acción. El trabajo infantil en la ciudad de México. Ciudad de México: Centro de Estudios Históricos-El Colegio de México.

Urías, Beatriz (2007). Historias secretas del racismo en México, 1920-1950. México: Tusquets.

Urteaga Castro-Pozo, Maritza (2011). La construcción juvenil de la realidad. Jóvenes mexicanos contemporáneos. México: Universidad Autónoma Metropolitana Unidad Iztapalapa. 